London

Cite this as: $B M J$ 2021;373:n996 http://dx.doi.org/10.1136/bmj.n996 Published: 21 April 2021

\title{
COVID-19
}

\section{What the new Health Security Agency means for public health}

In the midst of the pandemic the UK launched a new agency to protect public health. Emma Wilkinson reports from a Westminster Health Forum conference where experts debated the future of public health after covid and the agency's role

\section{Emma Wilkinson freelance journalist}

“Covid-19 has provided a powerful lens on existing health problems," said John Newton, director of health improvement at Public Health England, with an infectious disease pandemic coming on top of the ongoing epidemic of non-communicable disease. What we have now, he added, is a new context but "old problems."

Newton knows this well. He was speaking at a gathering of experts on public health at the Westminster Health Forum on 25 March, where they discussed the continuing recovery from covid-19 and the urgent need to tackle health inequalities. In the same week the government formally unveiled the new UK Health Security Agency to replace the much criticised PHE and that would also incorporate the functions of the Joint Biosecurity Centre and England's Test and Trace service. ${ }^{1}$

For those working in public health-who are used to demographic and socioeconomic shifts (and relevant policy making) happening over long periods of time - the past year has been like living in fast forward motion, said Jason Strelitz, director of public health in the east London borough of Newham. Successive waves of covid passed rapidly, and the system has been awash with detailed and real time community data, while local contact tracing teams have been speaking to thousands of residents, he said. "It has given us a microscope-really getting under the skin of health inequalities and seeing the way in which inequalities manifest in different ways in people's daily lives."

The Health Security Agency, originally announced as the National Institute for Health Protection back in August 2020, ${ }^{2}$ was a hot topic at the conference, given its remit to protect the UK against future external health threats such as infectious diseases, with a primary focus on covid-19. The move will see some health improvement functions in England returning to the Department of Health and Social Care for the first time since PHE was established in 2013.

\section{Tackling health inequalities}

A big question was how the new agency would approach the many health inequalities that seem to underlie the pandemic's differential impact. "We can't do health protection unless we tackle inequalities," said Strelitz, citing the case of one woman with covid-19 who lived in a shared house with 10 others and whose landlord had dismissed the risks.
"The incredibly strong evidence of the factors that support enduring transmission of the virus-jobs that can't be done from home, household overcrowding, the inability to isolate when necessary-is all powerfully correlated with deprivation," he said. He added that the agency will need to work alongside other organisations in the public health system to tackle the social determinants of health at a structural and individual level.

David Buck, senior fellow in public health and health inequalities at the King's Fund, agreed. “The fundamental lesson of covid is that health protection and infection control fail if they have nothing to say about inequality, poverty, and stigma,” he said.

Petra Meier, professor of public health at the University of Glasgow, outlined three overarching questions that the agency should answer: What stands in the way of healthy life expectancy gains? What is likely to be the long term impact of the pandemic on healthy life expectancy? What is it that we can do now?

Alice Wiseman, director of public health in Gateshead, said that covid had highlighted and exacerbated the growing gulf between England's haves and have nots. "The things that create the context where inequality thrives-poor quality housing, [lack of] employment, and poverty-are also the things that have prevented people from being able to fully protect themselves and their families and communities from covid," she said.

\section{Community level support}

Once the acute phase of the pandemic has passed there will be a need to continue to harness the power of communities, said Wiseman. "I was blown away by the community action during the first phase," she said. "United against a common enemy, people came together unaided, independent, and unfettered by process and bureaucracy."

The pandemic prompted change in community leadership and a re-engagement with social action, and now is the time to work with communities rather than imposing from the top, Wiseman added. "I do wonder why it took this crisis to push us as a society to do the right thing," she said.

Hannah Morgan, a GP and clinical director of Hayling Island and Emsworth Primary Care Network in Hampshire, said that primary care networks need to start dealing with the stark inequalities shown by the covid data. "We know that we can't do things the 
same for all of our populations and that the average isn't what' s important any more. What we need to do is make sure that we treat people in the way that they need to be treated and work with our communities to do that."

This might mean finding different ways to reach people for health checks, for example. "As primary care networks, we occupy that position in the system where we can notice the effects of when we're underserving a population and we can intervene," she said.

\section{Health first approach}

Yet public health will make progress after covid only with a cross government approach, participants said. "Many drivers of poor health are not the business of people with health in their title, so change will only happen if the new public health organisations are empowered to make health and wellbeing everybody's business," said Meier. "The NHS can only do so much."

Against the backdrop of the pandemic and the risk factors for severe covid disease, strategies for tackling obesity have come to the fore. ${ }^{3}$ Yet, despite 13 relevant public health strategies in the past 30 years, the prevalence of obesity has risen or remained static, because of a failure to successfully implement appropriate interventions, said Rebecca Elliott, prevention policy manager at the British Heart Foundation.

“There is no magic bullet,” she said. "[The pandemic] is an issue that provides a comprehensive strategy to address all of the drivers of obesity and the wider determinants that underpin ill health and health inequalities.”

More widely, experts call for urgent implementation of the recommendations of the Marmot review, ${ }^{4}$ but there are concerns about how the different local, regional, and national aspects of health protection and public health will join up.

The new agency faces several unanswered questions about how a body with a focus on health protection, and specifically infectious diseases, will incorporate work on health inequalities and meet the government's target of five extra years of healthy, independent life by 2035 . Some of PHE's remit, such as tackling obesity, is being moved to the new Office for Health Promotion within the Department of Health and Social Care. ${ }^{5}$

Several forum participants called for transparency from the agency and a greater willingness to communicate and allow ongoing use of timely and meaningful data such as those produced for the covid dashboard. Connections between the agency and the rest of the public health system need to be "hardwired," Buck argued.

Maggie Rae, president of the Faculty of Public Health, said the new structures in public health should start with local teams. "We really need to put that first and then build out to the regional and the national level," she said. And the local teams need to be adequately resourced, she added. "The settlement we've just had in the public health round is inadequate, considering the challenges that we face, and the Faculty of Public Health has joined with others to ask for a £1bn increase.

"I know the country's going to be in a very difficult financial situation, but we did manage to find £37bn for NHS Test and Trace.”

Care will need to be taken that the separation of health protection does not lead to it dominating other parts of public health, Rae said. "I don't think it can work in a silo."
Commissioning and peer review: Commissioned; not externally peer reviewed.

O'Dowd A. New agency will focus on preparing and protecting UK from future pandemics. BMJ 2021;372:n819. doi: 10.1136/bmj.n819 pmid: 33762256

2 lacobucci G. Public Health England is axed in favour of new health protection agency. BMJ 2020;370:m3257. doi: 10.1136/bmj.m3257 pmid: 32816824

3 Senthilingam M. Covid-19 has made the obesity epidemic worse, but failed to ignite enough action. BMJ2021;372:n411. doi: 10.1136/bmj.n411 pmid: 33664084

4 Marmot M. Health equity in England: the Marmot review 10 years on. BMJ2020;368:m693. doi: 10.1136/bmj.m693 pmid: 32094110

5 Department of Health and Social Care. New Office for Health Promotion to drive improvement of nation's health. 29 Mar 2021. https://www.gov.uk/government/news/new-office-for-healthpromotion-to-drive-improvement-of-nations-health.

This article is made freely available for use in accordance with BMJ's website terms and conditions for the duration of the covid-19 pandemic or until otherwise determined by BMJ. You may use, download and print the article for any lawful, non-commercial purpose (including text and data mining) provided that all copyright notices and trade marks are retained. 